\title{
Sustainability Scores for Investment Funds
}

By Jeroen Bos, CFA

"How sustainable is your investment fund?" is a question that asset managers hear with increasing regularity. This trend is hardly surprising given the rising use of environmental, social, and governance (ESG) factors in the investment process in recent years, along with the growing number of "sustainable" and "ethical" funds being launched across the industry. In response, investment funds that label themselves as "sustainable" or "ethical" need to demonstrate that they are true to their label. Sustainability ratings for investment funds can show investors which funds are living up to their name and which are not.

In 2016, Morningstar tried to address this question by developing a system for measuring investment funds' sustainability. Other firms, including MSCI, have followed suit, introducing their own sustainability measures and ratings. These developments help intensify fund managers' focus on ESG factors and sustainability. At the same time, such measures should be approached with caution. They can fail to capture certain aspects of sustainability (such as intention, engagement, and impact) and often include implicit biases regarding such factors as size and normalization. Drawing conclusions about investment funds' sustainability from a holdingsbased scoring model is more difficult than it might seem and should be done with care.

\section{METHODOLOGIES}

As an example, Morningstar's methodology calculates the weighted average ESG scores of all individual holdings in a portfolio. Based on data from sustainability researcher Sustainalytics, these scores reflect company policies and performance in areas such as carbon footprint, gender diversity, and independence of company directors, to name a few. The individual holding scores, corrected for any history of controversial company behavior, become the basis for a portfolio's sustainability score. The higher the ESG scores of the companies in an investment portfolio, the higher the portfolio's sustainability score. The investment fund is then compared with its peer group of funds from the same Morningstar category and given a ranking within this group of high, above average, average, below average, or low.

Clearly, sustainability ratings for investment funds bring some important benefits to the market. They increase transparency and facilitate fund comparisons. Furthermore, sustainability ratings can also show whether a fund really "walks its talk" and whether it does so consistently over time. But investors need to be aware that some of the current methodologies result in several limitations.

SIZE EFFECT. The first observation is that the largest companies have, on average, higher ESG scores than smallcap and mid-cap companies. This pattern has very little to do with smaller companies having less sustainable business models or exhibiting poorer

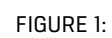

Mean ESG score per market cap decile

57

55

53

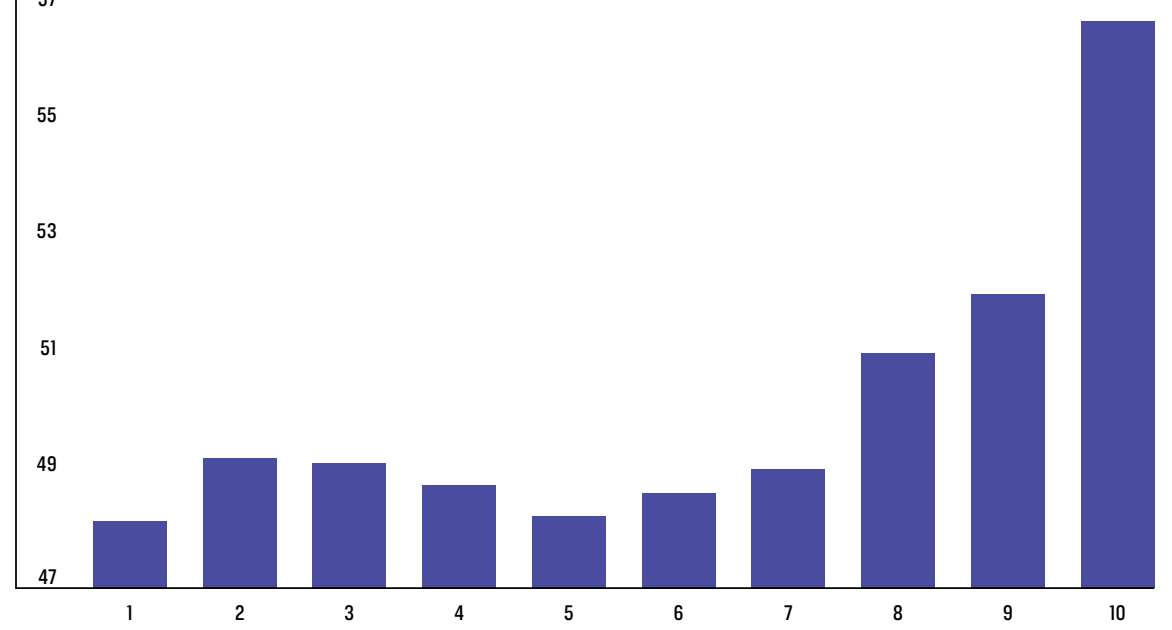

Sources: NN Investment Partners and the European Centre for Corporate Engagement, December 2015 behavior, nor does it result from less ambitious intentions around sustainability. In practice, the difference in average ESG scores often appears to be driven largely by these smaller companies having fewer resources to formalize their ambitions regarding specific targets, policies, reporting, and public relations. Thus, in most commonly used methodologies, higher-scoring investment funds can simply have a higher exposure to larger companies, a correlation that doesn't necessarily indicate higher exposure to more sustainable investments. Figure 1 clearly shows this size effect.

PRODUCT EXPOSURE. A second observation concerns the relatively high scores of companies whose activities seem less or not at all sustainable overall. Current methodologies typically score companies relative to their sector peers, often focusing more on the policies companies have in place than on the products or services they provide. The key implication of measuring ESG in this way is that even in sectors such as tobacco, oil and gas, and controversial weapons (cluster bombs, landmines, depleted 


\section{FIGURE 2}

ESG scores of the top $\mathbf{2 0} \%$ highest-scoring companies per sector

90

80

70

60

50

40

30

20

0
Tobacco

Energy

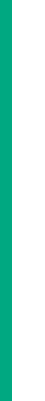

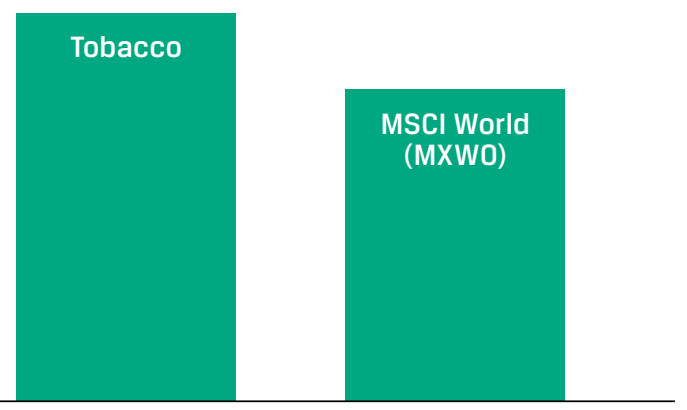

TOP 20\%'S ESG SCORE

Sources: NN Investment Partners and Sustainalytics

uranium, and chemical and biological weapons), a fair number of companies have rather high ESG scores, and owning shares of these companies can actually help improve a fund's sustainability rating. As Figure 2 shows, the top $20 \%$ highest-scoring companies in the energy universe have an average ESG score of about 77, well above the average score of 56 for the MSCI World Index. Similarly, the average score of the top $20 \%$ in the tobacco universe is also above the MSCI World average.

Of course, one can question the level of sustainability for investments in these sectors. Moreover, from a behavioral perspective, these companies often display a higher-than-average level of controversial behavior. Failure to consider the sustainability of a firm's actual activities is far from ideal.

PEER COMPARISON. A fund's sustainability score, and therefore its ranking, is often determined relative to other funds in its peer group. For example, a renewable energy fund could have a low or below-average sustainability score relative to other renewable energy funds, while a traditional energy fund might score above average or high relative to other traditional energy funds. Consequently, the renewable fund in this example could have a lower ranking than the traditional energy fund simply because of the peer groups against which they are measured. Clearly, this is something to consider when interpreting results for investment funds from thirdparty sustainability-rating agencies.
Research conducted by NN IP and the European Centre for Corporate
Engagement shows that one can best align sustainability and investment performance by focusing more on companies' behavior and changes in their ESG scores than on their absolute ESG scores. This study finds that investing in the companies with the highest ESG scores, adjusted for market cap, actually hampers investment performance, likely because these qualifications are usually widely known and therefore already reflected in the share price.

A much better approach is to focus on companies that have positive ESG momentum - companies with ESG scores that are average but improving. Figure 3 shows that focusing investments on companies with rising ESG scores improves Sharpe ratios across the spectrum. Furthermore, the biggest contribution to Sharpe ratios comes from investing in companies that score average or medium on ESG and have positive momentum. This dynamic holds true for changes in both the governance score and the aggregate ESG score. It also shows that ESG momentum has the least positive effect for companies that already score high on ESG. Following this momentum strategy, however, could sometimes actually lead to a lower sustainability fund score in current third-party fund methodologies, which often focus on the absolute ESG scores of a portfolio's holdings irrespective of ESG improvement momentum.

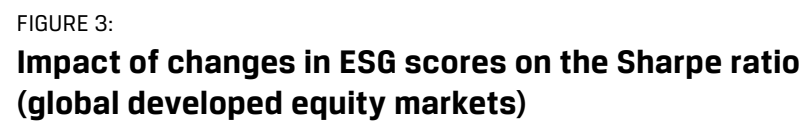

1.2

GOVERNANCE

$1.0+$ ESG

0.8

0.6

0.4

0.2

0.2

0.0

$-0.2$

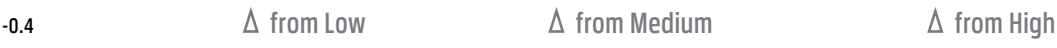

Sources: NN Investment Partners and the European Centre for Corporate Engagement 
NN IP's research also shows that focusing on a company's behaviorthat is, excluding companies that have shown controversial behavior-can improve risk-adjusted investment performance. These results are contrary to the common belief that reducing one's investment universe (and thereby reducing the opportunity set) will come at the expense of investment performance.

Data providers score companies on controversial behavior by rating them. For example, Sustainalytics rates companies from 1 to 5 , with category 5 defined as companies that have displayed the most controversial behavior. Our research shows that when exclusions are based on a company's behavior, this strategy can actually add to investment performance, as Figure 4 illustrates.

Some methodologies, such as Morningstar's, do take controversial behavior into account by imposing a small to moderate penalty on a company's final sustainability score. Still, a company's absolute ESG score is far more important for its final sustainability score and so is more heavily influenced by ESG targets, policies, and reporting than by the actual behavior that results from those targets and policies. With real sustainability as well as investment performance in mind, investors should consider focusing much more on the actual behavior of companies in which they invest rather than on absolute ESG scores.

In the end, behavior, not policy, is what matters and makes an impact. A great illustration of this principle comes from Volkswagen, which scored very well on ESG, largely because of its targets and policies. Eventually, the company was revealed to have engaged in illegal behavior, damaging its reputation and its market value.

\section{BEYOND THE NUMBERS}

Looking beyond ESG scores, investors should be aware of several other factors that are also of key importance when judging investment funds' sustainability. Regarding the companies in which these funds invest, these other factors include the intentionality of companies' behavior as well as its actual impact (positive or negative). Intentionality addresses the question of whether companies actually intend to do good through their products and solutions and through the way they operate in society. The right intentionality helps the sustainability of a company's longer-term business model.

The actual societal impact the companies are making is of course also very important. A company that has a new solution that can help the global energy transition is positively affecting society and the environment. This positive impact can also clearly help the sustainability of the company's business model, whereas a negative impact could result in a potentially unsustainable business model. Often, neither factor is fully captured in a company's ESG score, but both should be important when judging a fund's sustainability score.

An investment fund's engagement and active-ownership strategy is also a key aspect of sustainability. Through engagement with a company's board, the asset manager can help drive change and improvements to the company's performance on various sustainability factors. We feel engagement should also be taken

FIGURE 4:

Impact of exclusionary policies on risk-adjusted returns of portfolios (global developed equity markets)

0.8

0.82

0.80

0.78

0.74

0.74

0.72

Sources: NN Investment Partners and the European Centre for Corporate Engagement

\section{SUSTAINABILITY TRENDS TO EMPHASIZE} ety Netherlands.

Excl. Cat. 3+

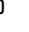

178

Excl. Cat. $4+$

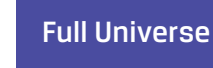

.

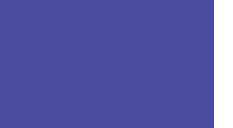

Excl. Cat. $4+$

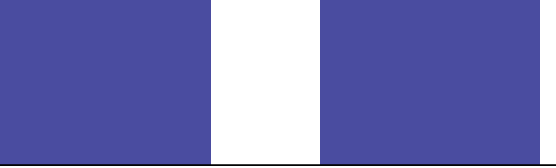

SHARPE RATIO into account when comparing the sustainability ratings of investment funds.

The introduction of sustainability ratings for investment funds is a positive development in the industry, one that should help increase transparency and fund comparison. It also confirms the irreversible growth of ESG integration and the increasing focus on sustainability within the sector. At the same time, investors need to exercise care when assessing fund sustainability ratings and be mindful of biases, such as firm size, a firm's activities, and relative peer group implications. Furthermore, the emphasis should shift toward judging the actual behavior of the companies in which a fund invests. A company's actions form the basis of its eventual impact on society and reveal the most about the longer-term sustainability of its business models and resulting investment performance. The asset management industry has taken important steps in the last 12 months on this front, and investors should expect continued momentum in the years to come. Jeroen Bos, CFA, is head of equities at NN Investment Partners and vice president of CFA Soci- 